Selahattin Ozsayan

Metin Taylan

http://dx.doi.org/10.21278/brod70207

\title{
ANOTHER BLOW ON THE TORN DOWN WALL-THE INCLINING EXPERIMENT
}

UDC 629.5.012.65:629.5.012.64:629.5.015.17

Review paper

\begin{abstract}
Summary
The classical method (namely inclining experiment) has been used to estimate the vertical center of gravity (VCG or more often KG) of ships for many years. This method is based on the assumption that the metacenter is unchanged in the calculation of $\mathrm{KG}$ when the vessel is heeled. However, ships built today have knuckles, chines, dead-rise which may give rise to excessive change in the water-plane. The location of the metacenter is changed on these vessels when heeled. Therefore, determination of the vertical center of gravity may be somewhat erroneous. In this study, three different methods based on the assumption of unchanged metacenter have been examined. Employing the Graphical method, Polar method and Generalized method, the KG values of all vessels can be calculated without any dependence on the metacenter. The three methods mentioned in this study were studied and applied on ten different ships. Furthermore, the results from the classical method compared with those obtained from the recently developed methods. Based on this comparison, it is observed that the new methods developed have similar results to the classical method. Therefore, these methods may be a good alternative to the inclining experiment in the future. Moreover, uncertainty analyses have been performed for the results obtained from the classical method just to realize if there are any critical GM values within the margin of error.
\end{abstract}

Keywords: $\quad$ Vertical center of gravity; Metacenter; Graphical method; Generalized method; Polar Method; Uncertainty analysis

\section{Introduction}

For the time being, the inclining experiment is the principal method for determining center of gravity of a ship. After a vessel is launched, an inclining experiment is performed to calculate especially lightship characteristics of the vessel, KG in particular. Likewise, this test should be repeated for existing ships following any major over-haul that will alter ship's weight considerably. 
The basis of the inclining experiment calculation, which is also known as the classical method, dates back to the end of $17^{\text {th }}$ century. Firstly, Hoste, a professor of mathematics, suggested the concept of inclining experiment in 1697 [1]. Furthermore, a practical method for the implementation of inclining experiment was defined by Bouguer in 1746 [2]. Using this classical method, $\mathrm{GM}_{0}$ of ships are to be obtained directly.

The classical method contains some assumptions intrinsically. Therefore, the validity of the classical method has been under discussion for many years. For small angles of heel, the immersed and emerged volumes are equal to each other when heeled. It is assumed that the metacenter is unchanged. The position of the metacenter depends on the unchanged water-plane area, equation (1).

$$
K M=K B+B M=K B+\frac{I_{W P}}{\nabla}
$$

The classical method is limited to small angles of heel. Especially, ships built in recent years have chines, knuckles and deadrise that can cause certain deviations in the metacenter. Alternative methods in calculating KG that has a great importance on ship stability have been emerged and improved in recent years.

One of the alternative methods of calculating $\mathrm{KG}$ of ships is the Graphical method proposed by O.O. Kanifolskyi and M.M. Konotopets in 2016 [3]. The Generalized method was proposed by R.J. Dunworth in 2013 and improved by R.J. Dunworth and A.C. Smith [5-8]. Another alternative method, the Polar method was proposed quite recently and refined by K. B. Karolius and D. Vassalos [4, 11, 12]. These alternative methods do not rely on the metacenter.

Since $\mathrm{KG}$ of ships is one of the most important governing parameter in stability and in turn safety, determination of it accurately is of great importance. Criticism on the inclining test has been around for so many years. Thus, pursuit for a more reliable method has gained momentum in recent years. In this study, KG of 10 vessels of various types are calculated by using three above-mentioned alternative methods and the results are compared with those from the classical method in order to lay out the differences if any. Additionally, uncertainty analyses have been employed on all 10 vessels to pinpoint the possible sources of error result from the classical method.

\section{The Inclining Experiment (Classical Method)}

The inclining experiment is carried out to find the vertical center of gravity of ships. The test is based on the measurement of angle of inclinations caused by moving the weights transversely placed on the deck. In some cases, ballast water may be used instead of solid weights as an alternative. In this case, selected tanks should be symmetrical (PS/SB) and trim of the ship should not change.

The inclining experiment is mandatory by the IMO's 2008 IS Code for every commercial ship above $24 \mathrm{~m}$ in length and all passenger ships.

\subsection{Application}

During the test, the vessel should float freely in water and mooring lines should be slack. The ship is then heeled by movements of test weights. These deflections are recorded by various means such as U-tubes, inclinometers or pendulums. If the inclining experiment is carried out using solid test weights, 8 shifts should be conducted as a standard required by 2008 IS Code. A sample sequence of the shifts are shown in Table 1. 
Table 1 Weight shift sequence

\begin{tabular}{|c|c|c|}
\hline \multirow{2}{*}{ Shift } & \multicolumn{2}{|c|}{ Shift of weights } \\
\cline { 2 - 3 } & PS & SB \\
\hline 0 & $\mathrm{w} 2, \mathrm{w} 4, \mathrm{w} 6$ & $\mathrm{w} 1, \mathrm{w} 3, \mathrm{w} 5$ \\
\hline 1 & $\mathrm{w} 4, \mathrm{w} 6$ & $\mathrm{w} 1, \mathrm{w} 2, \mathrm{w} 3, \mathrm{w} 5$ \\
\hline 2 & & $\mathrm{w} 1, \mathrm{w} 2, \mathrm{w} 3, \mathrm{w} 4, \mathrm{w} 5, \mathrm{w} 6$ \\
\hline 3 & $\mathrm{w} 6$ & $\mathrm{w} 1, \mathrm{w} 2, \mathrm{w} 3, \mathrm{w} 4, \mathrm{w} 5$ \\
\hline 4 & $\mathrm{w} 2, \mathrm{w} 4, \mathrm{w} 6$ & $\mathrm{w} 1, \mathrm{w} 3, \mathrm{w} 5$ \\
\hline 5 & $\mathrm{w} 1, \mathrm{w} 2, \mathrm{w} 3, \mathrm{w} 4, \mathrm{w} 6$ & $\mathrm{w} 5$ \\
\hline 6 & $\mathrm{w} 1, \mathrm{w} 2, \mathrm{w} 3, \mathrm{w} 4, \mathrm{w} 5, \mathrm{w} 6$ & \\
\hline 7 & $\mathrm{w} 1, \mathrm{w} 2, \mathrm{w} 4, \mathrm{w} 6$ & $\mathrm{w} 3, \mathrm{w} 5$ \\
\hline 8 & $\mathrm{w} 2, \mathrm{w} 4, \mathrm{w} 6$ & $\mathrm{w} 1, \mathrm{w} 3, \mathrm{w} 5$ \\
\hline
\end{tabular}

\subsection{Determination of $\mathrm{KG}$}

Since GM of a ship is obtained by the classical method directly, KG is calculated using equation (2).

$$
K G=K M-G M
$$

According to equation (1), the metacenter remains constant. $\mathrm{KM}$ in equation (2) is acquired from the hydrostatics at the test loading condition.

Ideally, prior to the inclining experiment, the ship should be in equilibrium with the weights placed symmetrically on deck without any heel and trim. When a weight is moved to a distance $d$, the center of gravity shifts from $G$ to $G_{1}$, Fig. 1 . Then $\tan \varphi$ is given by:

$$
\tan \varphi=\frac{G G_{1}}{G M}
$$

Re-arranging this equation, GM is obtained.

$$
G M=\frac{G G_{1}}{\tan (\varphi)}
$$

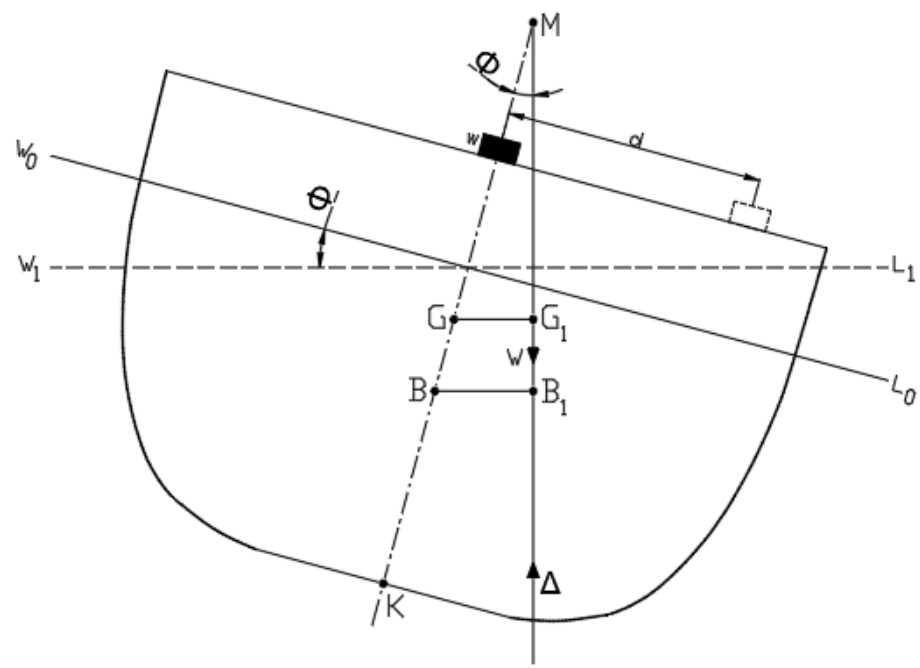

Fig. 1 Shift of center of gravity 
When a weight is moved, the center of gravity is shifted accordingly. In this case, $\mathrm{GG}_{1}$ is expressed by equation (5).

$$
G G_{1}=\frac{w \cdot d}{\Delta}
$$

Re-arranging equation (4), the final equation is obtained for GM.

$$
G M=\frac{w \cdot d}{\Delta \cdot \tan (\varphi)}
$$

In this expression, $\tan \varphi$ is calculated according to equation (7) for each pendulum and $\tan \varphi$ values calculated for each movement are averaged to minimize the error.

$$
\tan (\varphi)=\frac{\text { pen.deflection }}{\text { pen.length }}
$$

$\tan \varphi$ and moment values for all weight shift cases are calculated by the above equations. Then, w.d $/ \Delta$ is plotted against the corresponding $\tan \varphi$ for each weight shift and a linear line passing through these points is fitted according to the least squares method. The slope of the linear line gives GM. Alternatively, w.d is plotted against $\tan \varphi$ for each weight shift, as shown in Fig.2, and GM is calculated according to equation (8).

$$
G M=\frac{1}{\Delta \cdot R_{\text {slope }}}
$$

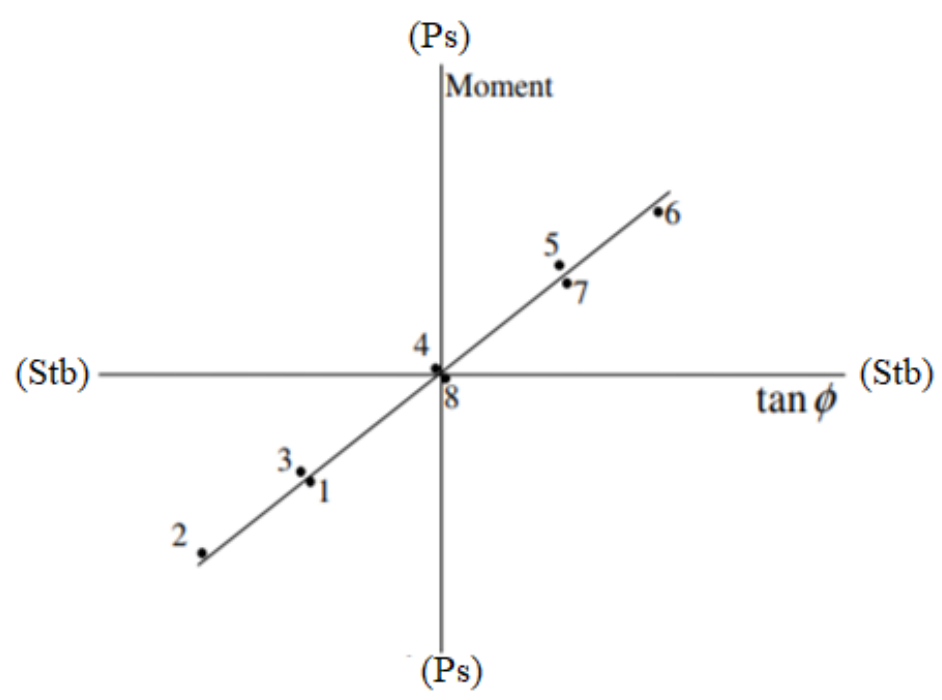

Fig. 2 Tan $\varphi$ - moment linear line

In case of slack liquid in tanks, it is necessary to introduce a free surface correction. Free surface moment (FSM) is calculated as in equation (9).

$$
F S M=\frac{l \cdot b^{3} \cdot \rho_{t}}{12 \cdot \Delta}
$$

Finally, $\mathrm{KG}$ is obtained as below.

$$
K G=K M-G M-F S M
$$

In addition, LCG and TCG are calculated as below. 


$$
\begin{aligned}
& L C G=L C B-\frac{\operatorname{Trim} \cdot M C T .100}{\Delta} \\
& T C G=T C B_{\varphi=0}+\tan (\varphi) \cdot G M
\end{aligned}
$$

\section{New Alternative Methods}

\subsection{Generalized method (Dunworth method)}

Generalized method was first proposed by R.J. Dunworth and A.C. Smith [3]. After each weight shift, the vessel reaches an equilibrium. Therefore, the vessel's righting and heeling moments must be equal.

$$
\begin{aligned}
& H_{\text {moment }}=R_{\text {moment }} \\
& \Delta . H Z=B_{M} \cdot G Z
\end{aligned}
$$
(15).

Since displacement and buoyancy forces are equal, equation (14) reduces to equation

$$
H Z=G Z
$$

Heeling arm (HZ) is obtained as below.

$$
H Z=\frac{w \cdot d \cdot \cos (\varphi)}{\Delta}
$$

The trigonometric relationships shown in Fig. 3 are used to obtain the righting arm of the ship.

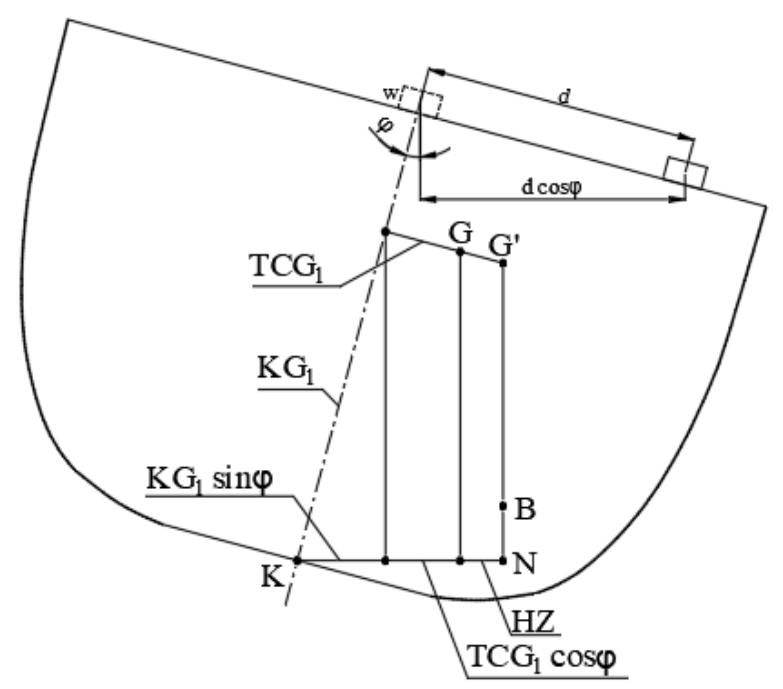

Fig. 3 Main parameters during heel [7]

$$
G Z=K N-K G_{1} \cdot \sin (\varphi)-T C G \cdot \cos (\varphi)
$$

When this equation is re-arranged using equation (15) and equation (16), KG is calculated as follows.

$$
K G_{1} \cdot \sin (\varphi)=K N-H Z-T C G_{1} \cdot \cos (\varphi)
$$




$$
K G_{1} \cdot \sin (\varphi)=K N-\frac{w \cdot d \cdot \cos (\varphi)}{\Delta}-T C G_{1} \cdot \cos (\varphi)
$$

Equation (18) reduces to equation (20) yielding $\mathrm{TCG}_{1}$ when $\varphi=0$.

$$
T C G_{1}=K N_{0}-H Z_{0}
$$

$\mathrm{KN}_{0}$ is obtained from the hydrostatics. Dunworth proposed that $\mathrm{HZ}_{0}$ is calculated by plotting HZ against heel angle $(\varphi)$ and a third-order polynomial passing through these points is fitted in accordance with the least squares method. When $\varphi=0, \mathrm{HZ}_{0}$ equals the intercept point on the y-axis of the trend line, Fig. 4 [7].

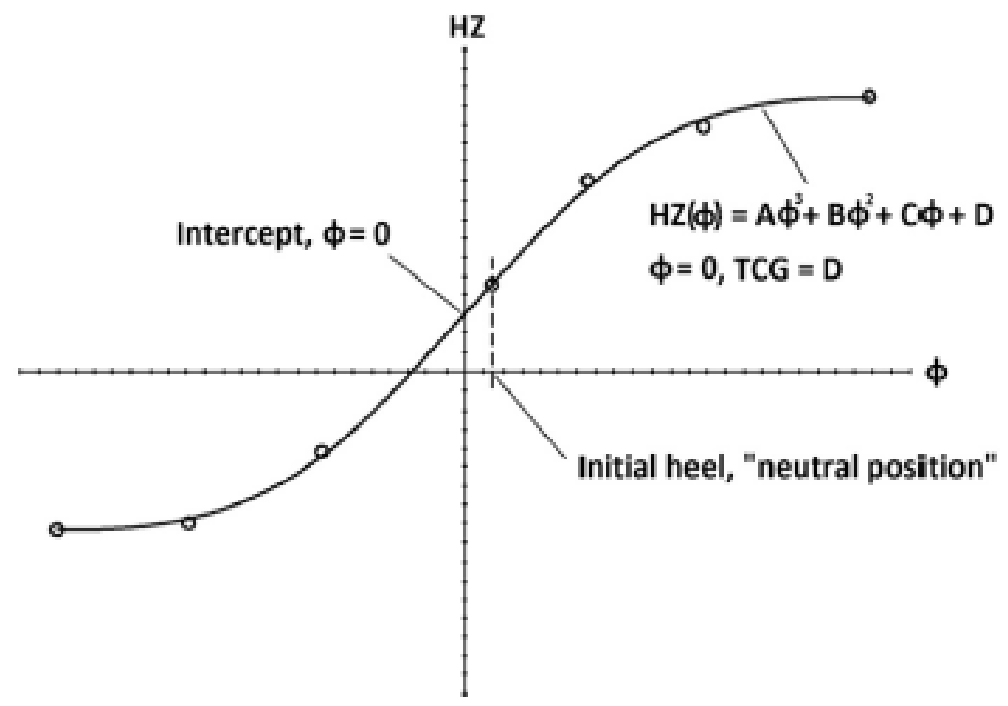

Fig. 4 Determination of $\mathrm{HZ}_{0}[4]$

\subsection{Graphical method}

Graphical method, which calculates KG directly, was proposed by Kanifolskyi and Konotopets in [3]. KN used in the calculation of $\mathrm{KG}$ are acquired from the hydrostatics. Kanifolskyi and Konotopets summarized the calculation of KG in 5 steps as shown in Fig. 5. The first step is to draw $\mathrm{KN}$ from the keel $(\mathrm{K})$. The second step is to draw a perpendicular to $\mathrm{KN}$. In the third step, HZ is calculated according to equation (16). In the fourth step, calculated $\mathrm{HZ}$ is placed in the correct position. That is, $\mathrm{HZ}$ arm is parallel to $\mathrm{KN}$ and intercepts the centerline. In the final step, KG is read off from the graph. These 5 steps must be repeated for all shifts of weights. In addition, the mean $\mathrm{KG}$ is calculated according to equation (21).

$$
K G=\frac{\sum_{i=1}^{n} K G_{i}}{n}
$$

As can be seen in Fig. 5, trigonometric relationships are driven from the sketch. $\mathrm{KG}$ is calculated according to the following sequence of equations:

$$
\begin{aligned}
& K G=\frac{K N-H Z}{\sin (\varphi)} \\
& K G \cdot \sin (\varphi)=K N-H Z
\end{aligned}
$$




$$
K G \cdot \sin (\varphi)=K N-\frac{w \cdot d \cdot \cos (\varphi)}{\Delta}
$$

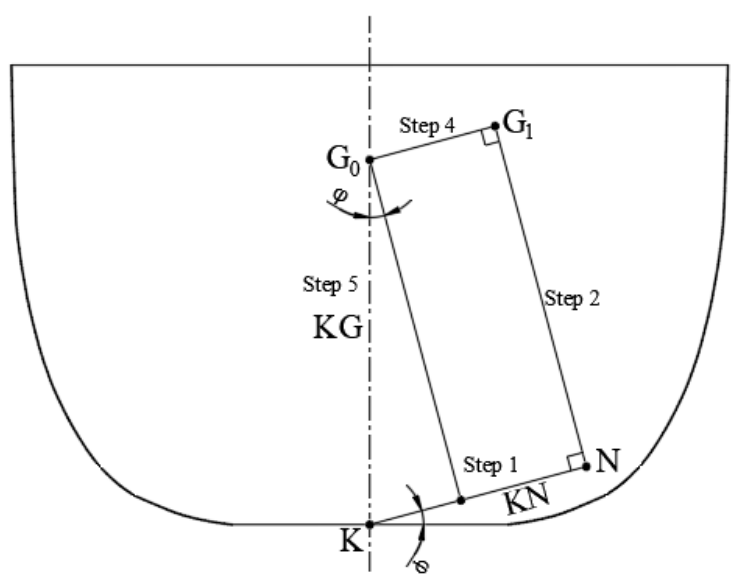

Fig. 5 Graphical method steps [4]

\subsection{Polar method}

Polar method is also a new method proposed by K. Karolius and D. Vassalos $[4,11,12]$. In this method, a line parallel to BM radius is considered. This line is shifted up to distance HZ, and represented in polar coordinates. In the initial condition, KG and TCG are located on this line. Moreover, the location of KG and TCG does not changed when each weight is shifted. Initial $\mathrm{KG}_{0}$ and $\mathrm{TCG}_{0}$ are fixed on this line. However, $\mathrm{TCG}$ is shifted up a distance $\mathrm{G}_{0} \mathrm{G}_{\mathrm{i}}$ when each weight is shifted, Fig. 6.

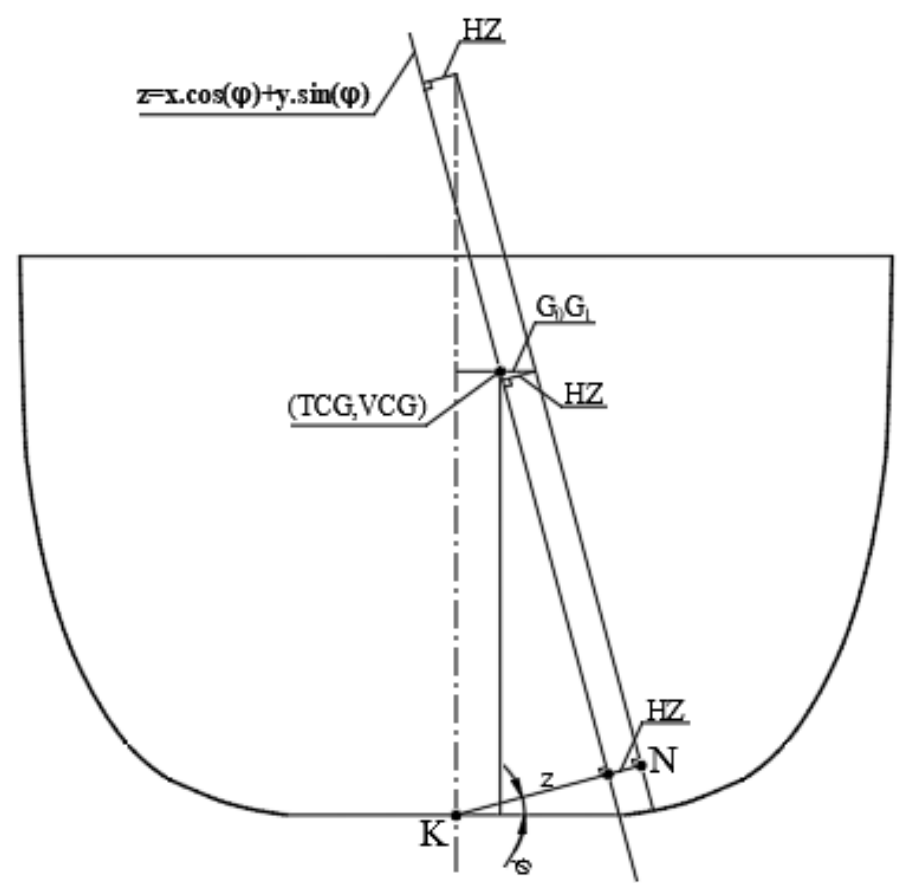

Fig. 6 The parameters of Polar method [4]

The equation of the straight line is given below. 


$$
z=x \cdot \cos (\varphi)+y \cdot \sin (\varphi)
$$

Equation (25) is rearranged to get equation (26). When equation (26) and equation (27) are combined, equation (28) is attained.

$$
\begin{aligned}
& z=T C G \cdot \cos (\varphi)+K G \cdot \sin (\varphi) \\
& z=K N-H Z \\
& K N-H Z=T C G \cdot \cos (\varphi)+K G \cdot \sin (\varphi)
\end{aligned}
$$

As mentioned above, $\mathrm{KG}_{\mathrm{i}}$ and $\mathrm{TCG}_{\mathrm{i}}$ for each shift $\mathrm{i}$ must be equal to $\mathrm{TCG}_{0}$ and $\mathrm{KG}_{0}$ respectively.

$$
\begin{gathered}
T C G_{0}=T C G_{i} \\
K G_{0}=K G_{i}
\end{gathered}
$$

When equation (28) is reorganized using equations (29) and (30), KG and TCG are found as follows:

$$
\begin{gathered}
K G=\frac{\left(K N_{i}-H Z_{i}\right) \cdot \cos \left(\varphi_{0}\right)-\left(K N_{0}-H Z_{0}\right) \cdot \cos \left(\varphi_{i}\right)}{\cos \left(\varphi_{0}\right) \cdot \sin \left(\varphi_{i}\right)-\sin \left(\varphi_{0}\right) \cdot \cos \left(\varphi_{i}\right)} \\
T C G=\frac{\left(K N_{i}-H Z_{i}\right) \cdot \sin \left(\varphi_{0}\right)-\left(K N_{0}-H Z_{0}\right) \cdot \sin \left(\varphi_{i}\right)}{\cos \left(\varphi_{i}\right) \cdot \sin \left(\varphi_{0}\right)-\sin \left(\varphi_{i}\right) \cdot \cos \left(\varphi_{0}\right)}
\end{gathered}
$$

Equation (29) and (30) are general forms which may be simplified according to state of the vessel during the inclining experiment. For example, if heeling arm in the initial position is zero, $\mathrm{HZ}_{0}$ vanishes. Furthermore, if the initial heel angle $\left(\varphi_{0}\right)$ is zero and ship is completely symmetrical, $\mathrm{KN}_{0}$ is also equal zero. Therefore, equations (29) and (30) are simplified as below.

$$
\begin{aligned}
& K G=\frac{\left(K N_{i}-H Z_{i}\right)}{\sin \left(\varphi_{i}\right)} \\
& T C G=0
\end{aligned}
$$

The above equations are the same equations seen in Graphical method. Therefore, the Graphical method is valid only for completely symmetrical vessels which have a limited heel angle in the initial condition. The KN used in the Polar method are to be obtained from a 3D stability software model of the ship. But they would still introduce additional errors. On the other hand, $\mathrm{HZ}_{0}$ is calculated as described in Section 3.1.

\section{Sample Ships}

In this study, 10 different ships having different sizes, hull forms and types with approved inclining experiment results have been used in order to observe the effect of various parameters on the results by these different methods.

This set of sample ships is comprised of two chemical tankers, two asphalt tankers, a service boat, a tug, a Ro-Ro, a container ship, a research vessel and a fast boat. The axis convention applied throughout this study is given in Table 2. The general characteristics of these vessels are supplied in Table 3. 
Table 2 Axis convention

\begin{tabular}{|l|c|}
\hline Positive x-direction & Aft $\rightarrow$ Forward \\
\hline Positive y-direction & Port $\rightarrow$ Starboard \\
\hline
\end{tabular}

Table 3 Sample vessel characteristics

\begin{tabular}{|l|c|c|c|c|c|c|c|c|}
\hline & $\mathbf{L}_{\mathbf{O A}}$ & $\mathbf{L}_{\mathbf{B P}}$ & $\mathbf{B}$ & $\mathbf{T}$ & $\mathbf{D}$ & $\Delta$ & $\mathbf{C}_{\mathbf{B}}$ & $\mathbf{A}_{\mathrm{WP}}$ \\
\hline & $\mathbf{m .}$ & $\mathbf{m}$ & $\mathbf{m .}$ & $\mathbf{m .}$ & $\mathbf{m .}$ & tons & & $\mathbf{m}^{\mathbf{2}}$ \\
\hline Chemical tanker-1 & 105 & 102.18 & 18 & 6.8 & 9.2 & 10021 & 0.774 & 1458 \\
\hline Chemical tanker-2 & 131.85 & 123.99 & 18.9 & 7.98 & 10.2 & 14834 & 0.770 & 1709.7 \\
\hline Asphalt tanker-1 & 119.9 & 116.8 & 19.4 & 7.35 & 10.8 & 14241 & 0.740 & 1649.8 \\
\hline Asphalt tanker-2 & 156.5 & 147.9 & 25 & 9.25 & 14.6 & 27960 & 0.800 & 2915.7 \\
\hline Service boat & 14.9 & 14.225 & 4.8 & 1.275 & 2.31 & 51.09 & 0.517 & 58.375 \\
\hline Tug & 17.55 & 17.55 & 8.4 & 3.1 & 3.25 & 235.95 & 0.520 & 88.45 \\
\hline Ro-Ro & & 120 & 19.4 & 4.88 & & & & 1902.2 \\
\hline Research vessel & & 56.45 & 8.8 & 3.95 & & & & \\
\hline Fast boat & & 13.06 & 4.04 & 0.765 & & 17.355 & 0.6620 & \\
\hline Container & & 134.47 & 22.6 & 3.576 & & 17887 & 0.620 & \\
\hline
\end{tabular}

\section{Adoption of New Methods}

The calculation of KG is performed according to the methods described in Section 3 on the sample vessels. The details of the calculations are given for research vessel only as an example in the following subsections respectively. The same procedures have been applied to the other ships for all methods but only the final results were revealed for space limitation.

\subsection{The graphical method}

The graphical method KG calculations are shown below.

Table 4 Research vessel-Graphical method procedure

\begin{tabular}{|c|c|c|c|c|c|c|c|c|}
\hline Shift & $\tan \varphi$ & $\varphi$ & $\sum \varphi$ & $\varphi$ & HZ & KN & $\operatorname{Sin} \varphi$ & KG.Sin $\varphi$ \\
\hline & mean & degree & degree & radian & $\mathrm{m}$ & $\mathrm{m}$ & & \\
\hline & 0 & 0 & -1.0000 & -0.0175 & 0 & -0.0754 & -0.0175 & -0.0754 \\
\hline 1 & 0.0164 & 0.9423 & -0.0577 & -0.0010 & 0.0068 & -0.0043 & -0.0010 & -0.0112 \\
\hline 2 & 0.0304 & 1.7428 & 0.7428 & 0.0130 & 0.0137 & 0.0560 & 0.0130 & 0.0423 \\
\hline 3 & -0.0164 & -0.9423 & -1.9423 & -0.0339 & -0.0069 & -0.1465 & -0.0339 & -0.1396 \\
\hline 4 & -0.0006 & -0.0335 & -1.0335 & -0.0180 & 0.0000 & -0.0779 & -0.0180 & -0.0779 \\
\hline 5 & -0.0149 & -0.8553 & -1.8553 & -0.0324 & -0.0068 & -0.1399 & -0.0324 & -0.1331 \\
\hline 6 & -0.0291 & -1.6663 & -2.6663 & -0.0465 & -0.0137 & -0.2011 & -0.0465 & -0.1874 \\
\hline 7 & 0.0153 & 0.8753 & -0.1247 & -0.0022 & 0.0069 & -0.0094 & -0.0022 & -0.0163 \\
\hline 8 & 0.0000 & 0.0000 & -1.0000 & -0.0175 & 0.0000 & -0.0754 & -0.0175 & -0.0754 \\
\hline
\end{tabular}

$\tan \varphi$ values given in Table 4 were found from the ratio of pendulum deviations to the pendulum length from the inclining experiment report. Since three pendulums were used in the inclining experiment, readings from these three pendulums were averaged. In the fourth column, heel angle of the third column and initial heel angle are collected. In sixth column, HZ 
is calculated according to equation (16). $\mathrm{KN}$ in Table 4 is obtained from ship's stability booklet. Finally, KG.sin $\varphi$ is calculated according to equation (23).

Results that are obtained from Table 4 is plotted in Fig. 8. Slope of the linear line provides KG. Free surface correction, weights to be added and removed for calculations of lightship KG are shown in Table 5.

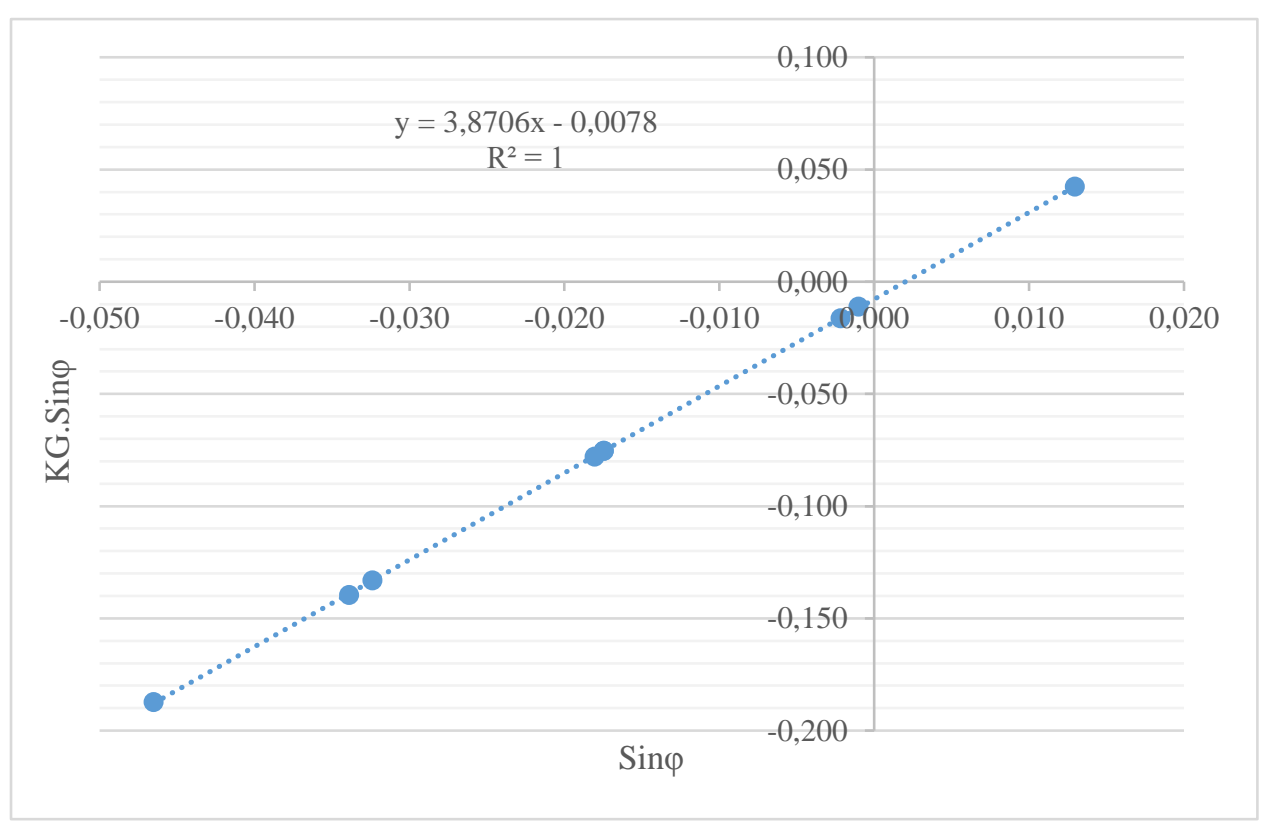

Fig. 7 Research vessel Graphical method, KG.sin $\varphi$ vs $\sin \varphi$

Table 5 Research vessel-Graphical method KG value

\begin{tabular}{|l|c|c|c|}
\hline & Weight (t) & KG (m) & FSM (ton.m) \\
\hline Ship as inclined & 1167.602 & 3.8706 & 104.025 \\
\hline FS corrections & & -0.089 & \\
\hline Fluid KG & 1167.602 & 3.782 & \\
\hline Total items to remove & -295.85 & 2.051 & \\
\hline Lightship & 871.75 & 4.369 & \\
\hline
\end{tabular}

5.2 The Generalized method

Table 6 Research vessel-Generalized method procedure

\begin{tabular}{|c|c|c|c|c|c|c|c|c|}
\hline Shift & $\tan \varphi$ & $\varphi$ & $\sum \varphi$ & $\varphi$ & $\mathrm{HZ}$ & $\mathrm{KN}$ & $\operatorname{Sin} \varphi$ & KG.Sin $\varphi$ \\
\hline & mean & degree & degree & radian & $\mathrm{m}$ & $\mathrm{m}$ & & \\
\hline & 0.0000 & 0.0000 & -1.0000 & -0.0175 & 0.0000 & -0.0754 & -0.0175 & -0.0678 \\
\hline 1 & 0.0164 & 0.9423 & -0.0577 & -0.0010 & 0.0068 & -0.0043 & -0.0010 & -0.0036 \\
\hline 2 & 0.0304 & 1.7428 & 0.7428 & 0.0130 & 0.0137 & 0.0560 & 0.0130 & 0.0499 \\
\hline 3 & -0.0164 & -0.9423 & -1.9423 & -0.0339 & -0.0069 & -0.1465 & -0.0339 & -0.1320 \\
\hline 4 & -0.0006 & -0.0335 & -1.0335 & -0.0180 & 0.0000 & -0.0779 & -0.0180 & -0.0703 \\
\hline 5 & -0.0149 & -0.8553 & -1.8553 & -0.0324 & -0.0068 & -0.1399 & -0.0324 & -0.1255 \\
\hline 6 & -0.0291 & -1.6663 & -2.6663 & -0.0465 & -0.0137 & -0.2011 & -0.0465 & -0.1798 \\
\hline 7 & 0.0153 & 0.8753 & -0.1247 & -0.0022 & 0.0069 & -0.0094 & -0.0022 & -0.0087 \\
\hline 8 & 0.0000 & 0.0000 & -1.0000 & -0.0175 & 0.0000 & -0.0754 & -0.0175 & -0.0678 \\
\hline
\end{tabular}


The generalized method utilizes the spreadsheet shown in Table 6. The steps in the table are the same as the graphical method except the last column. In the last column, KG. $\sin \varphi$ is calculated according to equation (18). Fig. 8 is used to obtain $\mathrm{HZ}$ in this equation. Using a third order polynomial approximation, $\mathrm{HZ}_{0}$ is found to be $-0.0023 \mathrm{~m}$.

Graphical representation of the results in Table 6 is depicted in Fig. 9. The slope of the linear line gives KG. Free surface correction, weights to be added and removed for the lightship $\mathrm{KG}$ are shown in Table 7.

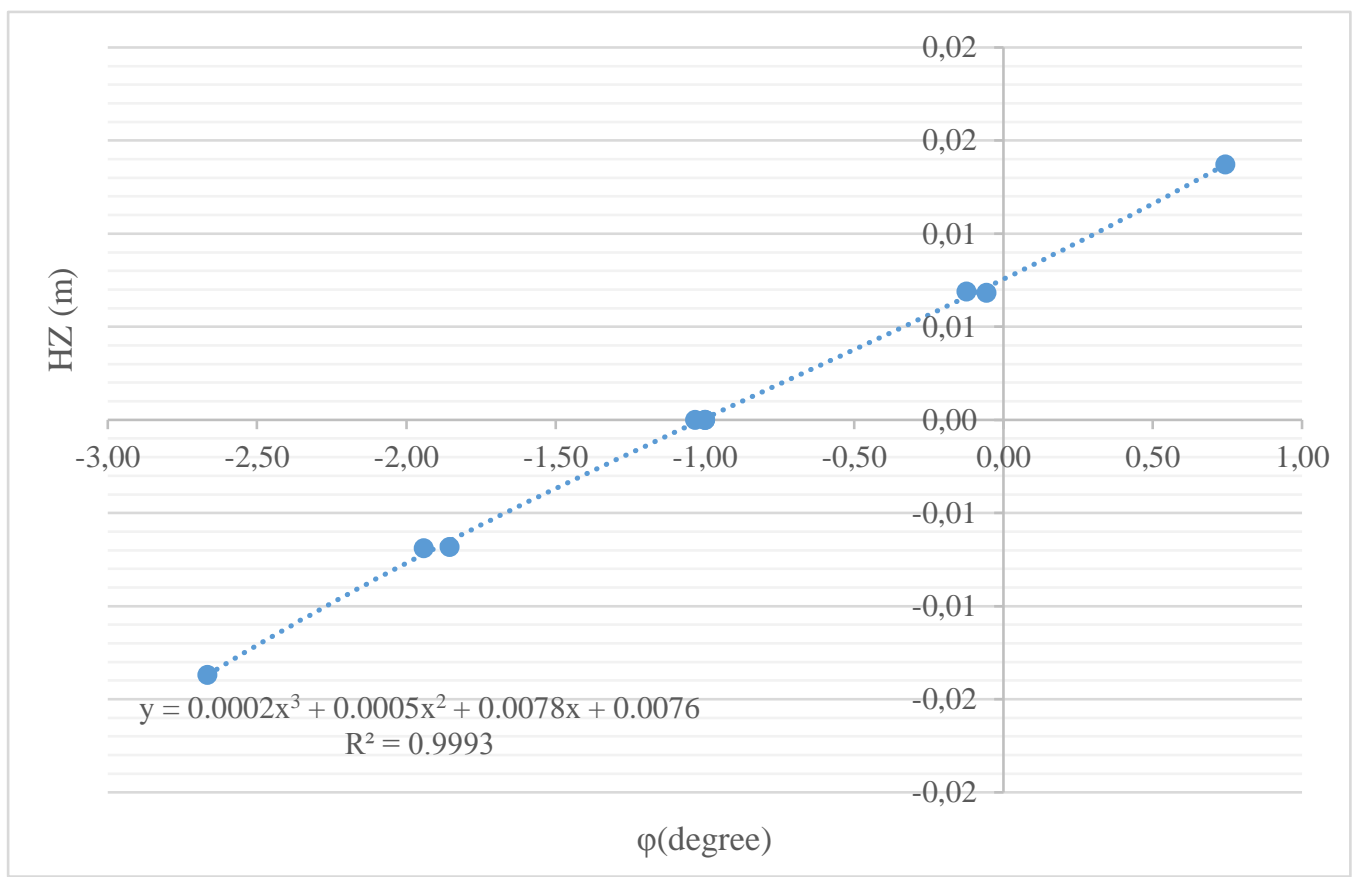

Fig. 8 Research vessel-Generalized method, HZ vs $\varphi$

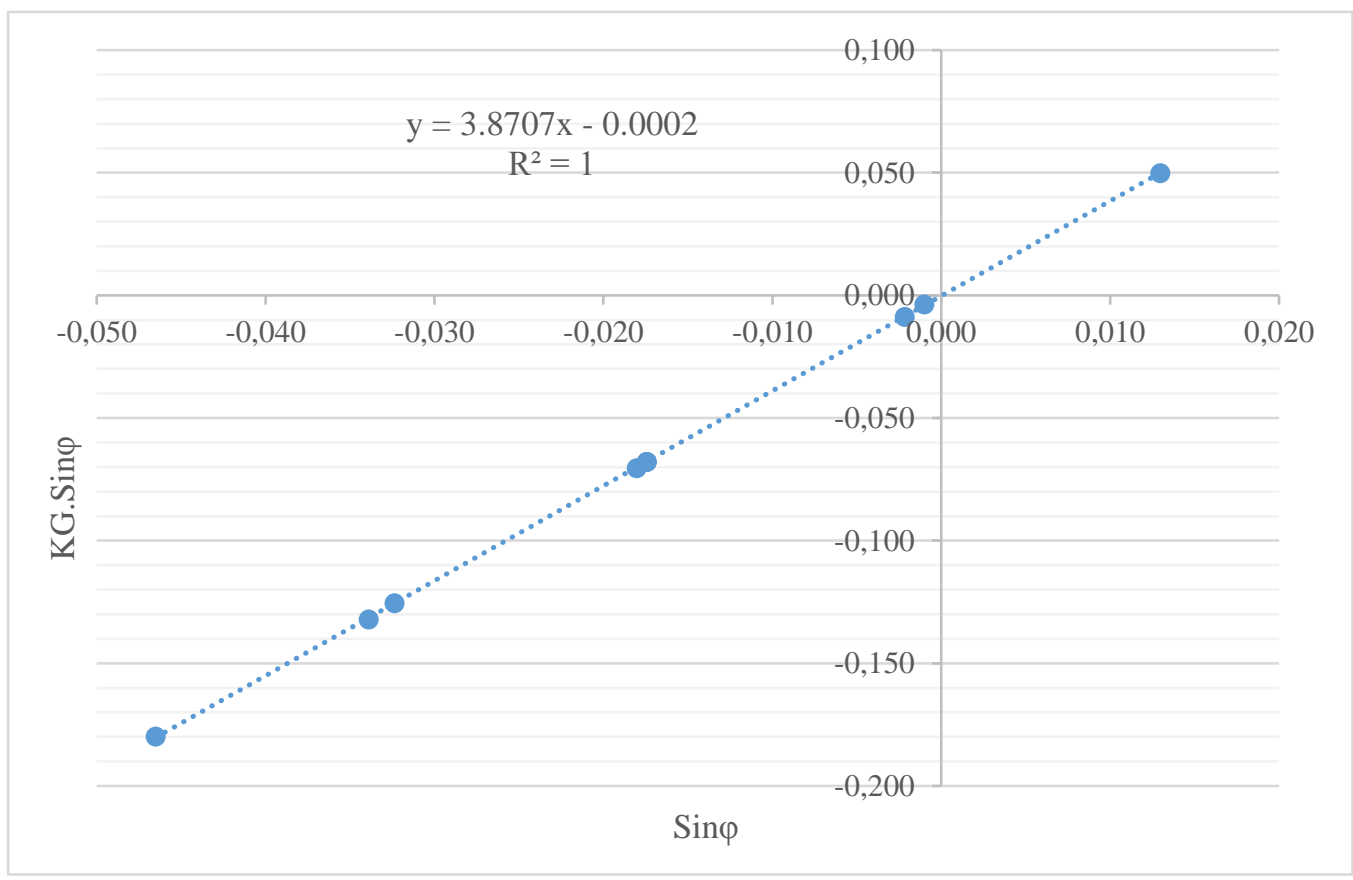

Fig. 9 Research vessel-Generalized method, KG.sin $\varphi$ vs $\sin \varphi$ 
Table 7 Research vessel-Generalized method, KG value

\begin{tabular}{|l|c|c|c|}
\hline & Weight (t) & KG (m) & FSM (ton.m) \\
\hline Ship as inclined & 1167.602 & 3.8707 & 104.025 \\
\hline FS corrections & & -0.089 & \\
\hline Fluid KG & 1167.602 & 3.782 & \\
\hline Total items to remove & -295.85 & 2.051 & \\
\hline Lightship & 871.75 & 4.369 & \\
\hline
\end{tabular}

\subsection{Polar method}

The procedure to calculate KG in Polar method is shown in Table 8. The steps up to last two columns are similar to the graphical and generalized methods. Unlike other two methods, $\sin \left(\varphi_{\mathrm{i}^{-}} \varphi_{0}\right)$ is used. KG.sin $\left(\varphi_{\mathrm{i}^{-}} \varphi_{0}\right)$ in the last column is calculated according to equation (31). $\mathrm{HZ}_{0}$ in equation (31) is the same as the Generalized method and equal to $-0.023 \mathrm{~m}$.

Table 8 Research vessel-Polar method procedure

\begin{tabular}{|c|c|c|c|c|c|c|c|c|c|}
\hline Shift & $\tan \varphi$ & $\varphi$ & $\sum \varphi$ & $\varphi$ & $\mathrm{HZ}$ & $\mathrm{KN}$ & $\operatorname{Sin} \varphi$ & $\sin \left(\varphi_{\mathrm{i}}-\varphi_{0}\right)$ & KG.sin $\left(\varphi_{\mathrm{i}}-\varphi_{0}\right)$ \\
\hline & mean & degree & degree & radian & $\mathrm{m}$ & $\mathrm{m}$ & & & \\
\hline 0 & 0.0000 & 0.0000 & -1.0000 & -0.0175 & 0.0000 & -0.0754 & -0.0175 & 0.0000 & -0.0678 \\
\hline 1 & 0.0164 & 0.9423 & -0.0577 & -0.0010 & 0.0068 & -0.0043 & -0.0010 & 0.0164 & -0.0036 \\
\hline 2 & 0.0304 & 1.7428 & 0.7428 & 0.0130 & 0.0137 & 0.0560 & 0.0130 & 0.0304 & 0.0499 \\
\hline 3 & -0.0164 & - & -1.9423 & -0.0339 & -0.0069 & -0.1465 & -0.0339 & -0.0164 & -0.1320 \\
\hline 4 & -0.0006 & - & -1.0335 & -0.0180 & 0.0000 & -0.0779 & -0.0180 & -0.0006 & -0.0703 \\
\hline 5 & -0.0149 & - & -1.8553 & -0.0324 & -0.0068 & -0.1399 & -0.0324 & -0.0149 & -0.1255 \\
\hline 6 & -0.0291 & $\begin{array}{c}- \\
0.6663\end{array}$ & -2.6663 & -0.0465 & -0.0137 & -0.2011 & -0.0465 & -0.0291 & -0.1797 \\
\hline 7 & 0.0153 & 0.8753 & -0.1247 & -0.0022 & 0.0069 & -0.0094 & -0.0022 & 0.0153 & -0.0087 \\
\hline 8 & 0.0000 & 0.0000 & -1.0000 & -0.0175 & 0.0000 & -0.0754 & -0.0175 & 0.0000 & -0.0678 \\
\hline
\end{tabular}

After KG.sin $\left(\varphi_{\mathrm{i}^{-}} \varphi_{0}\right)$ is calculated, results are plotted in Fig.10. Slope of linear line gives KG. Finally, free surface correction, weights to be added and removed for the lightship KG are shown in Table 9.

Table 9 Research vessel- Polar method KG value

\begin{tabular}{|l|c|c|c|}
\hline & Weight (t) & KG (m) & FSM (ton.m) \\
\hline Ship as inclined & 1167.602 & 3.8692 & 104.025 \\
\hline FS corrections & & -0.089 & \\
\hline Fluid KG & 1167.602 & 3.780 & \\
\hline Total items to remove & -295.85 & 2.051 & \\
\hline Lightship & 871.75 & 4.367 & \\
\hline
\end{tabular}




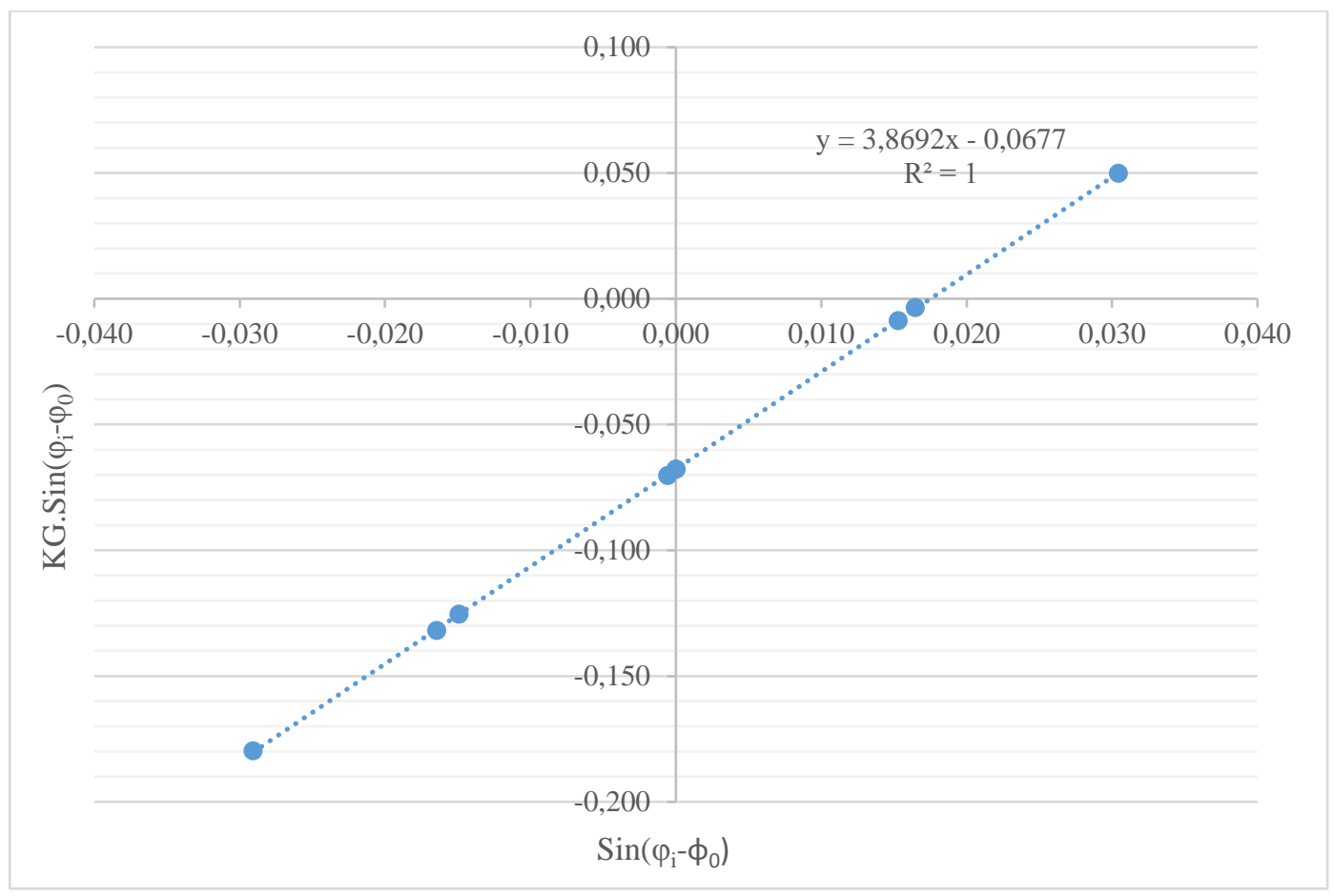

Fig. 10 Research vessel, Polar method KG. $\sin \left(\varphi_{\mathrm{i}^{-}}-\varphi_{0}\right) \mathrm{vs} \sin \left(\varphi_{\mathrm{i}^{-}} \varphi_{0}\right)$

\section{Comparison and Analysis of the Results}

In this section, KG of 10 different vessels obtained from four different methods are presented in Table 10. KG obtained according to the classical method is taken as a reference. The items shown as difference are the difference between the $\mathrm{KG}$ values obtained from the alternative methods and by the classical method.

When differences are examined, the highest difference was $8.4 \%$ between Graphical and Generalized methods in research vessel. In polar method, this difference is $8.3 \%$. In chemical tanker (1), the difference in three methods is obtained as $-6.4 \%$. For tugboat, similar to chemical tanker (1) in the Graphical method and Generalized methods, however, a positive $6.4 \%$ difference was calculated. This difference is $6.3 \%$ in polar method. For asphalt tanker (1), in the polar and graphical method, the difference is in the order of $-5.1 \%$ and in the Generalized method in the order of $-5.0 \%$. In the case of fast boat, the difference is calculated as $-5.1 \%$ in the polar method and $-5.0 \%$ in the graphical and Generalized methods. The difference for the container ship is $4.5 \%$ in all methods. Asphalt tanker (2) shows a difference of $-3.8 \%$ in all methods. In Ro-Ro vessel and service boat, the difference is $-1.8 \%$ in all methods evaluated except for polar method. This difference is $-1.9 \%$ in polar method. Finally, the closest result is calculated with $0.2 \%$ difference in all methods for chemical tanker (2).

Small differences between 3 methods indicate that these methods can be applied to different ships having different hull geometries, sizes and characteristics with a good level of confidence. Graphical representation of comparison of all three methods is shown in Fig. 11. 
Table 10 Comparison of results by methods

\begin{tabular}{|c|c|c|c|c|c|c|c|c|c|c|}
\hline \multirow{3}{*}{$\begin{array}{l}\text { Sample } \\
\text { Ships }\end{array}$} & \multirow{2}{*}{$\begin{array}{c}\text { Classical } \\
\mathrm{KG}\end{array}$} & \multicolumn{3}{|c|}{ Graphical } & \multicolumn{3}{|c|}{ Polar } & \multicolumn{3}{|c|}{ Generalized } \\
\hline & & $\mathrm{KG}$ & Diff.. & Diff.. & $\mathrm{KG}$ & Dif. & Dif. & $\mathrm{KG}$ & Diff. & Diff. \\
\hline & $(\mathrm{m})$ & $(\mathrm{m})$ & $(\mathrm{mm})$ & $(\%)$ & $(\mathrm{m})$ & $(\mathrm{mm})$ & $(\%)$ & $(\mathrm{m})$ & $(\mathrm{mm})$ & $(\%)$ \\
\hline $\begin{array}{l}\text { Chemical } \\
\text { Tanker (1) }\end{array}$ & 7.449 & 6.969 & -480 & -6.4 & 6.969 & -480 & -6.4 & 6.969 & -480 & -6.4 \\
\hline $\begin{array}{c}\text { Asphalt } \\
\text { Tanker (1) }\end{array}$ & 8.466 & 8.034 & -431 & -5.1 & 8.038 & -428 & -5.1 & 8.038 & -427 & -5.0 \\
\hline $\begin{array}{c}\text { Service } \\
\text { Boat }\end{array}$ & 1.663 & 1.632 & -31 & -1.8 & 1.632 & -31 & -1.9 & 1.633 & -30 & -1.8 \\
\hline $\begin{array}{c}\text { Asphalt } \\
\text { Tanker (2) }\end{array}$ & 8.501 & 8.177 & -324 & -3.8 & 8.176 & -325 & -3.8 & 8.177 & -323 & -3.8 \\
\hline $\begin{array}{l}\text { Chemical } \\
\text { Tanker (2) }\end{array}$ & 8.153 & 8.170 & 17 & 0.2 & 8.169 & 16 & 0.2 & 8.170 & 17 & 0.2 \\
\hline Tug & 3.425 & 3.643 & 218 & 6.4 & 3.641 & 216 & 6.3 & 3.643 & 218 & 6.4 \\
\hline Ro-Ro & 9.413 & 9.241 & -172 & -1.8 & 9.240 & -173 & -1.9 & 9.241 & -172 & -1.8 \\
\hline Research & 4.031 & 4.369 & 338 & 8.4 & 4.367 & 336 & 8.3 & 4.369 & 338 & 8.4 \\
\hline Fast boat & 1.294 & 1.228 & -66 & -5.1 & 1.228 & -66 & -5.0 & 1.228 & -66 & -5.1 \\
\hline Container & 9.926 & 10.375 & 449 & 4.5 & 10.375 & 449 & 4.5 & 10.375 & 449 & 4.5 \\
\hline
\end{tabular}

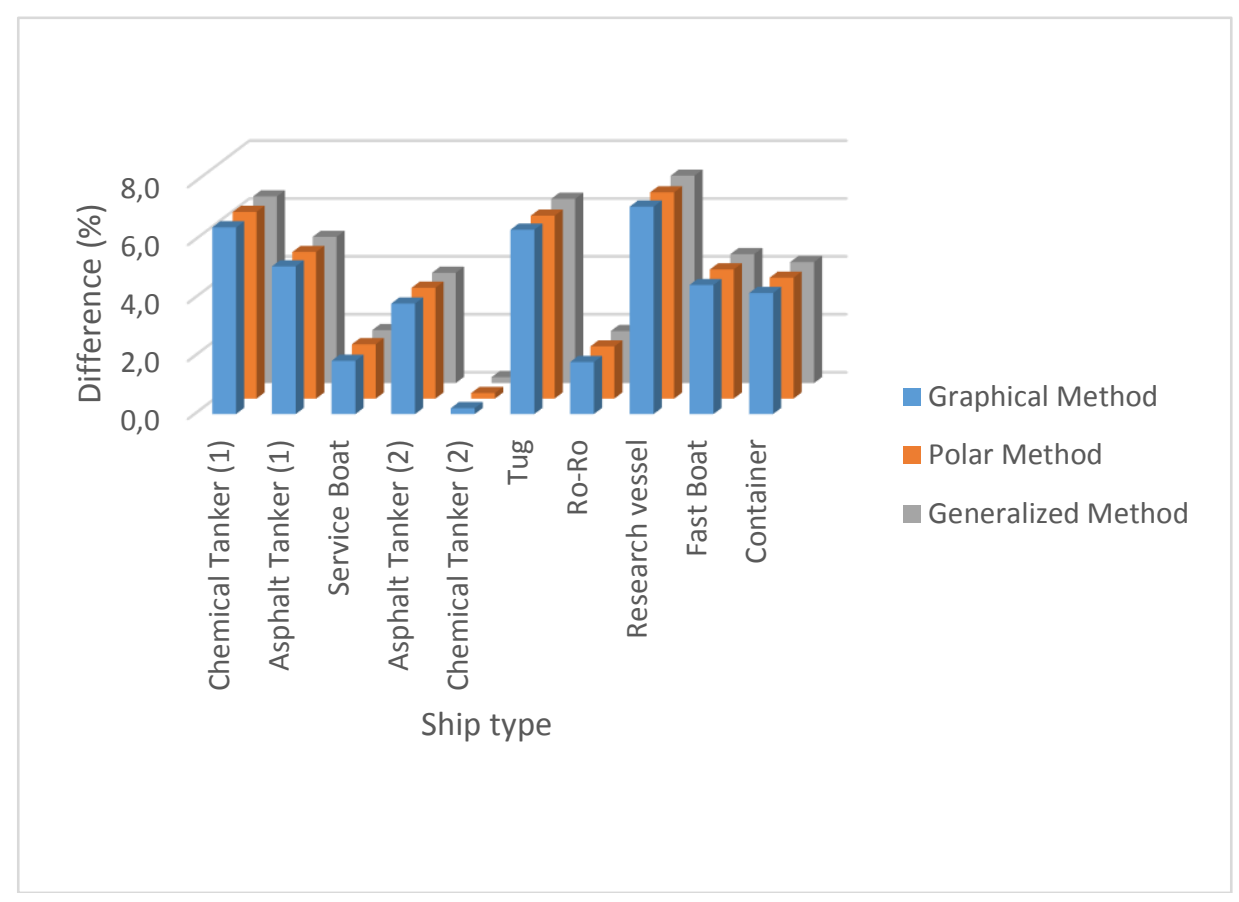

Fig. 11 Comparison of three methods

\section{Uncertainty Analysis}

There are a number of uncertainties in the inclining experiment conducted for the determination of the vertical center of gravity $(\mathrm{KG})$ of ships. Since it involves certain measurements and human interference, this experiment more likely contains some errors. These uncertainties and errors start with draft readings before and after the test and continue with the 
assumptions made during the calculations. The following may be shown as sources of error; wind, current, wave, human error, errors of measurement devices etc. All these errors may accumulate from the beginning to the end of the inclining experiment and may result in significant nonconformities in $\mathrm{KG}$ and GM.

It is assumed that metacenter is fixed when the vessel is heeled. However, most of the ships that are built today having knuckles, chines and dead-rise which result in deviations in the water-plane area. This in turn causes errors in the lightship KG and GM.

On the contrary, three new methods discussed in this study are not based on the assumption that the metacenter is fixed. Therefore, the uncertainties caused by the change of metacenter are eliminated.

\subsection{Uncertainty analysis procedure and results}

In this section, a range of source of uncertainties and errors such as draft reading, displacement, heel angle, wind, wave etc. are examined. The effect of these uncertainties has been applied to all ships used in the study [10]. Uncertainties in inclining experiment have been investigated by many other researchers such as Wilczynski et al [13] and Woodward et al [14]. They examined the uncertainty in GM which results from the bias and accuracy errors pertinent to each measured and calculated variable.

As a procedure, the uncertainty in the slope of the best fit linear line is determined first. Then, the uncertainty in displacement is calculated according to equation (8). Uncertainties of vessel draft, calculated molded volume, density, molded vs. as-built volume are reflected to the uncertainty of the displacement. The uncertainty in $\mathrm{GM}\left(\mathrm{U}_{\mathrm{GM}}\right)$ is found after the uncertainty of displacement $\left(\mathrm{U}_{\Delta}\right)$ and slope of line $\left(\mathrm{U}_{\text {Slope }}\right)$ are determined.

$$
\left(\frac{U_{G M}}{G M}\right)=\sqrt{\left(\frac{U_{\text {slope }}}{\text { slope }}\right)^{2}+\left(\frac{U_{\Delta}}{\Delta}\right)^{2}}
$$

Or, in shorthand;

$$
U_{G M}=\sqrt{U_{\text {slope }}^{2}+U_{\Delta}^{2}}
$$

Since KG is composed of various hydrostatic parameters, the uncertainty in KG (as inclined) is given as;

$$
U_{K G}=\sqrt{U_{K B}^{2}+U_{B M}^{2}+U_{G M}^{2}}
$$

$\mathrm{BM}$ on the other hand is the ratio of moment of inertia and volume having the uncertainty of;

$$
U_{B M}=\sqrt{U_{I}^{2}+U_{\nabla}^{2}}
$$

Similarly, uncertainty of each parameter can be determined using its constituents in the same manner as explained above.

Next, errors from KB, BM and experimental weights are calculated. Finally, Uncertainty of lightship KG is determined. The details of uncertainty analysis applied to chemical tanker (1) are given in Table 11 below. 
Table 11 Result of the uncertainty analysis for research vessel

\begin{tabular}{|l|c|c|c|}
\hline \multicolumn{1}{|c|}{ Parameter } & $\begin{array}{c}\text { Measured/ } \\
\text { calculated value }\end{array}$ & Uncertainty & Units \\
\hline Slope (tangent/moment) & 265.550 & 0.316 & $1 / \mathrm{t} . \mathrm{m}$ \\
\hline Molded vs. as-built volume (v) & 1143.587 & 0.043 & $\mathrm{~m}^{3}$ \\
\hline Vessel drafts & 3.948 & 0.019 & $\mathrm{~m}$ \\
\hline Calculated molded volume (m) & 1143.587 & 22.872 & $\mathrm{~m}^{3}$ \\
\hline Displacement volume (V) & 1143.587 & 23.612 & $\mathrm{~m}^{3}$ \\
\hline Density & 1.021 & 0.002 & $\mathrm{t} / \mathrm{m}^{3}$ \\
\hline Displacement ( $\Delta$ ) & 1167.602 & 24.171 & $\mathrm{t}$ \\
\hline As- inclined GM & 0.445 & 0.009 & $\mathrm{~m}$ \\
\hline As- inclined KG & 3.529 & 0.076 & $\mathrm{~m}$ \\
\hline Lightship KG & 4.031 & 0.183 & $\mathrm{~m}$ \\
\hline
\end{tabular}

Note: All uncertainties are at $95 \%$ confidence level.

$$
\begin{aligned}
& \mathrm{GM}=0.445 \pm 0.009 \mathrm{~m} \\
& \mathrm{KG}=4.031 \pm 0.183 \mathrm{~m}
\end{aligned}
$$

The same procedure has been applied to all sample vessels and tabulated results are supplied in Table 12 below. Uncertainties in GM and KG are also depicted graphically in Fig. 12 and Fig.13 respectively.

Table 12 Comparison of uncertainty analyses for sample ships

\begin{tabular}{|l|c|c|c|c|}
\hline \multicolumn{1}{|c|}{ Sample Ships } & $\begin{array}{c}\text { GM } \\
(\mathbf{m})\end{array}$ & $\begin{array}{c}\text { error } \\
( \pm \mathbf{m})\end{array}$ & $\begin{array}{c}\text { KG } \\
(\mathbf{m})\end{array}$ & $\begin{array}{c}\text { error } \\
( \pm \mathbf{m})\end{array}$ \\
\hline Chemical tanker-1 & 4.206 & 0.09 & 7.449 & 0.47 \\
\hline Chemical tanker-2 & 2.971 & 0.06 & 8.153 & 0.34 \\
\hline Asphalt tanker-1 & 2.30 & 0.05 & 8.466 & 0.31 \\
\hline Asphalt tanker-2 & 7.441 & 0.16 & 8.501 & 0.31 \\
\hline Service boat & 1.266 & 0.04 & 1.663 & 0.09 \\
\hline Tug & 1.998 & 0.04 & 3.425 & 0.11 \\
\hline Ro-Ro & 1.256 & 0.03 & 9.413 & 0.29 \\
\hline Research vessel & 0.445 & 0.01 & 4.031 & 0.18 \\
\hline Fast boat & 0.828 & 0.04 & 1.294 & 0.14 \\
\hline Container & 2.44 & 0.05 & 9.926 & 0.35 \\
\hline
\end{tabular}

Uncertainty analysis provides a possible margin of error which is inherent to inclining experiment. Table 12 depicts the errors in GM and KG for the sample vessels. This may be important especially for ships whose margin of stability is critical.

Wilczynski [13] also provided a sample calculation on the uncertainty of GM of an OSV having length $44.5 \mathrm{~m}$. and $\mathrm{GM}=6.593 \mathrm{~m}$. from the test. He obtained $\pm 0.122 \mathrm{~m}$. uncertainty in GM which is quite comparable with the uncertainties in chemical tanker (1) and asphalt tanker (1). Woodward et al [14] compared the uncertainties of four ships (with a fixed reference $\mathrm{GM}=0.15 \mathrm{~m}$.): buoy tender $0.15 \pm 0.15 \mathrm{~m}$., superyacht $0.15 \pm 0.033 \mathrm{~m}$., supply ship $0.15 \pm 0.047 \mathrm{~m}$., 
containership $0.15 \pm 0.029 \mathrm{~m}$. and ropax $0.15 \pm 0.077 \mathrm{~m}$. These results are also in line with the results obtained for the sample vessels in Table 12.

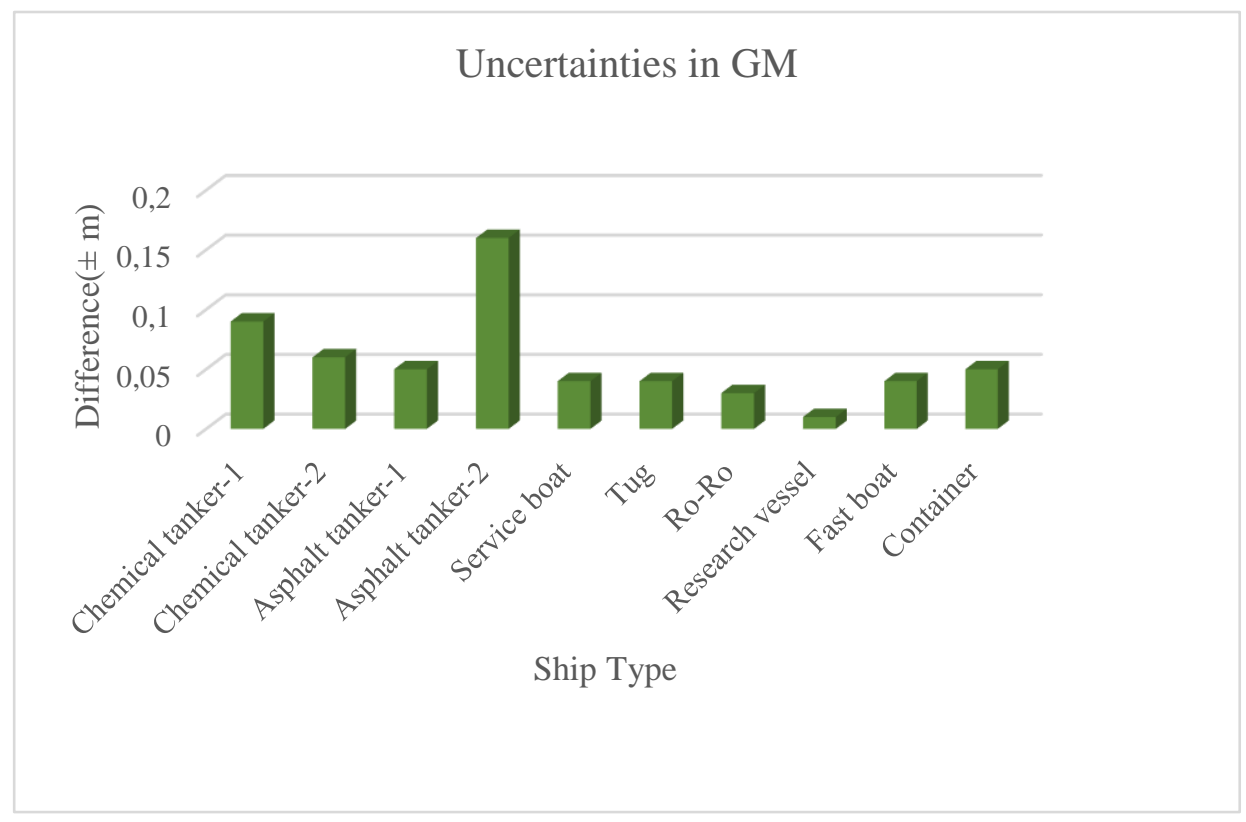

Fig. 12 Uncertainty in GM

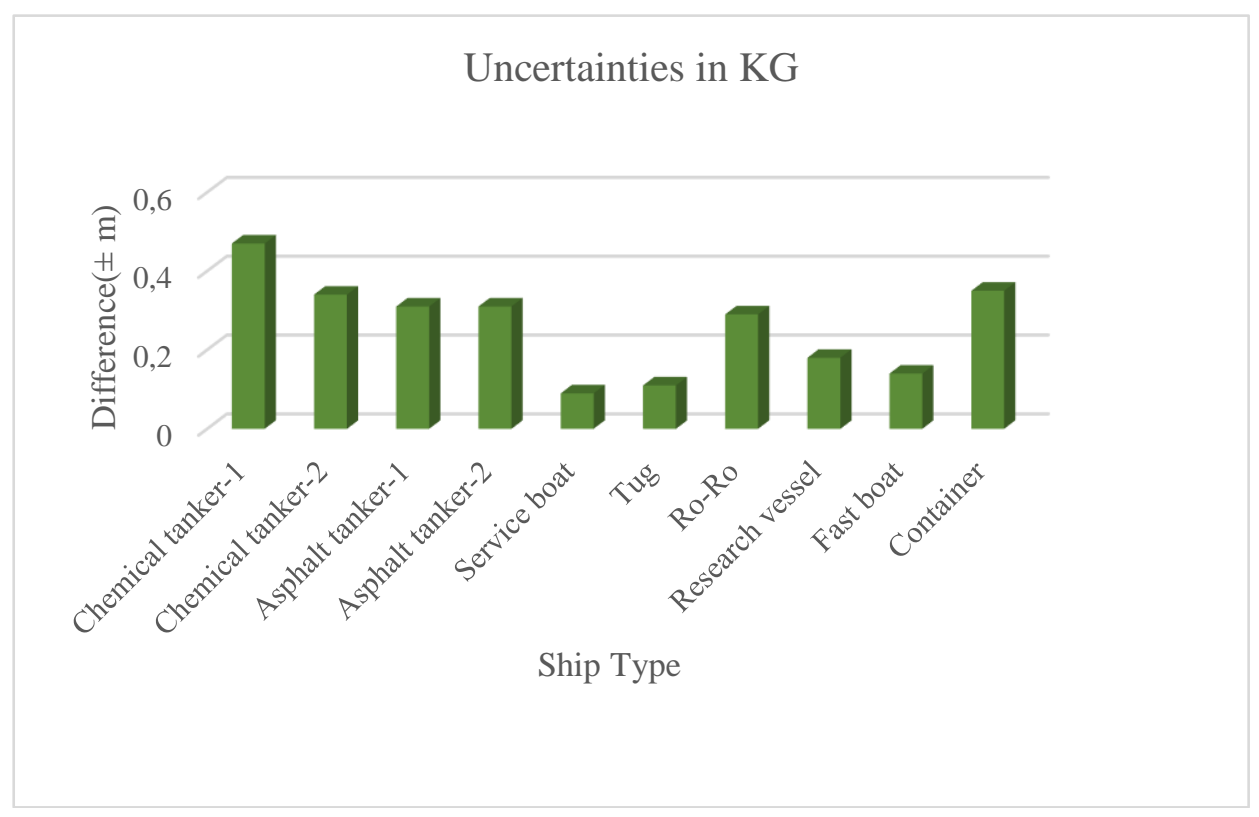

Fig. 13 Uncertainty in $\mathrm{KG}$

\section{Conclusions}

In this study, Graphical method, Generalized method and Polar method developed in recent years have been applied to ten different sample ships to determine the lightship KG values and the pertinent calculations are presented in details.

When the results of the methods are evaluated, the three anew proposed methods give very similar results for KG. Having compared the classical method results with the newly developed three methods, the biggest difference is seen as $8.4 \%$ in the research vessel. This 
discrepancy may be attributed to the fact that the research vessel has such a hull form which plays an important role on the water-plane area. The closest results are attained within the range of $0.2 \%$ for chemical tanker (2) having a high $\mathrm{C}_{\mathrm{B}}$.

The generalized method reveals slightly different results since it does not take into account the initial heel angle $\left(\varphi_{0}\right)$. Among the three methods discussed, the most diverse results are obtained from the graphical method. This may be because the graphical method does not take into account the transverse center of gravity (TCG) and the initial heel angle $\left(\varphi_{0}\right)$.

The outcome of the analysis on the vessels such as asphalt tankers, chemical tanker (2), Ro-Ro and container ship reveals that there is a difference of less than $5 \%$ in $\mathrm{KG}$. However, there is a difference in the order of 6-8\% in $\mathrm{KG}$ calculated with the newly developed methods. An uncertainty analysis has been carried out on the results from the inclining experiment in order to observe whether they fall within the above-mentioned margins. This fact is really important for the vessels having small GM values barely complying with the regulations.

It is the authors' belief that the difference between the results of the inclining experiment and the results of the other methods taken into consideration emanating from the assumptions made during the conventional inclining experiment in addition to the inherent errors from various sources such as draft, pendulum readings etc.

As a conclusion, certain amount of error is inevitable especially in determining $\mathrm{KG}$ from the inclining experiment. Therefore, in order to minimize the error, these proposed methods may be considered as an alternative since they do not depend on the uncertainties confronted in the test. Furthermore, these methods are much easier to apply to any ship regardless of hull form, size or type. However, it is not easy to draw definitive generalized conclusions from this comparative analysis.

Nevertheless, the readers should be bear in mind that the comparative analysis carried out in this study relies on the fact that the results from the inclining experiment are taken as a reference since the absolute error free GM is not known. Obviously, the main objective of this paper is not to determine the exact value of GM but to compare results of various methods using different test vessels. Although, it is mandatory to perform inclining experiment for ships today, it seems feasible that one of these methods may be considered by IMO in the future to supersede the current inclining experiment after further research and benchmark studies.

\section{REFERENCES}

[1] Hoste, P.,1697. Théorie de la Construction des Vaisseaux (Theory of the Construction of Vessels), Arisson \& Posule, Lyon.

[2] Bouguer, P., 1746. Traité du Navire, de sa Construction et de ses Mouvemens (Treatise of the Ship, its Construction and its Movements), Jombert, Paris.

[3] Kanifolskyi, Konotopets, 2016. The Graphical Method for Analysis of the Inclining Test. Mod. Inf. Technol. Sphere Security Defence 3 (27), 37-39.

[4] Karolius, K., Vassalos, D., 2018. Tearing down the wall- The inclining experiment. Ocean Engineering, 148, 442-475. https://doi.org/10.1016/j.oceaneng.2017.11.037

[5] Dunworth, R., 2013. Up Against the Wall, in International Maritime Conference, Pacific 2013: Sydney, Australia.

[6] Dunworth, R., 2014. Back Against the Wall. RINA Transactions (International Journal of Small Craft Technology). 156(B2), pp. 99-106.

[7] Dunworth, R., 2015. Beyond the Wall, in International Conference on the Stability of Ships and Ocean Vehicles, Glasgow.

[8] Smith, A.C., Dunworth, R. and Helmore, P.J., 2015. Towards the Implementation of a Generalized Inclining Method for the Determination of the Centre of Gravity, Sydney, Australia.

[9] International Maritime Organization, 2008. "Part B Annex I of the International Code on Intact Stability 2008”, as adopted in IMO Res. MSC.267(85), pp. 68-86. 
[10] U.S. Department of Transportation, 2016. MSC Technical review and analyses of the SS El Faro. Washington, US.

[11] Karolius, K.B. and Vassalos, D., 2018. Weight and Buoyancy is the Foundation in Design: Get it Right, 13th International Marine Design Conference, Helsinki, Finland, 10-14 June 2018.

[12] Karolius, K.B. and Vassalos, D., 2018. Second Generation Calculation Method for Use in the Inclining Experiment, 13th International Conference on the Stability of Ships and Ocean Vehicles, Japan, 16-21 Sept. 2018.

[13] Wilczynski, V., Patrick H. Knowles, P.H. and Diehl, W.J., 1998, Uncertainty Analysis of a Vessel's Metacentric Height, Probabilistic Safety Assessment and Management Conference, 1998, New York, NY, US.

[14] Woodward, M.D., Rijsbergen, M.V., Hutchinson, K.W. and Scott, A., 2016, Uncertainty Analysis Procedure for the Ship Inclining Experiment, Ocean Engineering, (114) pp.79-86. https://doi.org/10.1016/j.oceaneng.2016.01.017

Submitted: $\quad$ 18.11.2018. $\quad$ Selahattin Ozsayan (e-mail: ozsayan@itu.edu.tr)

Istanbul Technical University, Department of Naval Architecture and Marine

Accepted: $\quad$ 03.05.2019. Engineering, Istanbul, Turkey

Metin Taylan (e- mail: taylan@itu.edu.tr)

Istanbul Technical University, Department of Naval Architecture and Marine Engineering, Istanbul, Turkey 